\title{
Importância da Psicomotricidade na Construção do saber no Ensino Superior do Centro Universitário de Volta Redonda - UniFOA
}

\author{
Autor Hilda Torres Falcão (Ciências da Saúde - UniFOA \\ hilda.falcao@foa.com.br \\ Cíntia Delesposti Ramos \\ cinthiadelespoti@yahoo.com.br \\ Denian Alexandre Pires \\ dnagomes@ig.com.br \\ Jozilene da Silva \\ jozilbranca@hotmail.com \\ Márcia Christine da Silva Peixoto \\ bilulmile@yahoo.com.br
}

\section{Resumo}

Tendo em vista o contexto atual do Ensino Superior no mundo contemporâneo, a proposta deste trabalho é enfocar, numa visão interacionista e dialética, a importância entre a Psicomotricidade e a construção do saber; sensibilizar a comunidade acadêmica a estar mais atenta a fim de perceber e interessar-se pelo discente na sua totalidade e, também, a refletir sobre a importância da inter-relação (docente - discente) tão fundamental para a construção do saber, possibilitando com isso um desenvolvimento intelectual ajustado aos integrantes da vida acadêmica .

Palavras chave: Ensino Superior; Psicomotricidade; Construção do Saber.

"The importance of Psichomotricity in the construction of the knowledge in the higher education"

\begin{abstract}
Based on the current context of higher education in the contemporary world, this work has the aim to focus on the importance and correlation between Psicomotricity and learning acquisition in higher education. The approach used in this proposal was based on the interactive and dialectics view, in order to
\end{abstract}


emphasize the importance of the faculty awareness, concerning with building a good rapport among professors and students in the school setting. Thus, theses elements are considered, in this study, as a basic foundation for the acquisition of academic knowledge and social interaction in the school environment.

Key words: higher education, Psicomotricity, acquisition of academy knowledge.

\section{1 - Introdução}

Vive-se um momento de profundas e rápidas transformações, principalmente no tocante ao novo modelo de construção do saber em que o homem só pode ser entendido na sua totalidade: cognição, ação, movimento, emoção, espiritualidade; numa relação indissociável com o meio físico do qual faz parte (LUCKESI, 2003)

Nesse contexto, os educadores do ensino superior devem repensar sua prática educativa, principalmente em relação às questões que dizem respeito à importância da psicomotricidade na construção do saber.

A psicomotricidade constitui uma abordagem multidisciplinar do corpo e da motricidade humana. Em termos de matriz teórica, ela compreende um ramo interdisciplinar de conhecimentos, no qual se cruzam várias contribuições cientificas: conceitos psicobiológicos, psiquiátricos, psicossomáticos, psicolingüísticos, fenomenológicos e sociológicos.

Nessa relação, ao mesmo tempo pessoal e social, a psicomotricidade pretende atingir a ação educativa, criando condições para aquisições das habilidades que facilitarão a interrelação entre o homem e o saber, através do corpo em movimento se dirigindo ao ser em sua totalidade, em seus aspectos motores, emocionais, afetivos, intelectuais e expressivos, dentro de um contexto sócio-histórico-cultural.

Neste sentido, cabe ao docente o desafio de garantir o movimento, o fluxo de energia, a riqueza do processo, a troca.

Tendo em vista o contexto atual do ensino superior no mundo contemporâneo, temos com este trabalho a intenção de sensibilizar a comunidade acadêmica a estar mais atenta, a perceber e interessar-se pelo discente na sua totalidade.

Esta será uma pesquisa bibliográfica básica e exploratória que discorrerá sobre vários assuntos envolvendo a temática da psicomotricidade e a construção do saber no ensino superior a fim de despertar o interesse da comunidade acadêmica e terá seus pressupostos teóricos baseados em diversos autores tendo como principais Vitor da Fonseca e Edgar Morim. Ambos demonstram uma concepção holística do ser humano, numa visão interacionista e dialética entre o saber e a psicomotricidade. 


\section{2 - Revisão da Literatura}

\section{1 - A História e a Importância da Psicomotricidade}

A Psicomotricidade está associada ao processo de evolução do corpo, que é o objeto e sujeito de estudo dessa ciência.

As primeiras pesquisas que dão origem ao campo psicomotor correspondem a um enfoque eminentemente neurológico. Somente em 1907, Ernest Dupré, a partir de seus estudos clínicos na observação de pacientes com debilidade mental e debilidade motora, dá partida à psicomotricidade. Sabe-se, por diversas fontes histórias, que no rótulo do mental incluíam-se dificuldades ligadas ao cognitivo e ao relacional. "Entre certas alterações mentais e as alterações motoras correspondentes existe uma união tão íntima que parece constituir verdadeiras paralelas psicomotoras”, afirma Dupré.

De 1907 até 1947, o imperialismo neurológico já não era tão forte, mas a psicomotricidade, apenas muito superficialmente, ia integrando os trabalhos de Freud (1913), de Wallon (1934) e de Piaget (1936). Em contrapartida recebeu a influência de pedagogos, como Montessori (1936), Descendres, Decloy e outros.

Entre 1947 e 1959 fica clara a passagem da Psicomotricidade do campo exclusivo da neurologia e da pedagogia para uma aliança com a psiquiatria, graças às lideranças dos professores Julian de Ajuriaguerra e René Diathine.

Foi Ajuriaguerra que, em 1959, fez a ligação e aprofundou os conhecimentos, frutos da inter-relação da neurologia, da psicologia do desenvolvimento e da psicanálise. Devido a este trabalho a Psicomotricidade saiu da visão cartesiana e do paralelismo e passou a ser grafada sem hífen, sem separação; uma unidade.

No início da década de 60, Ajuriaguerra definiu terapia Psicomotora: "É uma técnica que por intermédio do corpo em movimento dirigi-se ao ser na sua totalidade. Ela não visa à readaptação por setores e, muito menos, a supervalorização do músculo, mas a fluidez do corpo no seu meio. Seu objetivo é permitir ao indivíduo melhor sentir-se e, através de um maior investimento da corporalidade, situar-se no espaço, no tempo, no mundo dos objetos e chegar a uma modificação e a uma harmonização com o outro”.

No Brasil, a história da psicomotricidade vem acontecendo de maneira semelhante à história mundial. Os primeiros documentos registram seu nascimento na década de 50, quando Gruspum já mencionava atividades motoras indicadas no tratamento de distúrbios de aprendizagem.

Em 1980 surgiu a Sociedade Brasileira de Terapia Psicomotora que mais tarde muda seu nome para Sociedade Brasileira de Psicomotricidade (SBP) que define a psicomotricidade como: "Ciência que tem por objeto o estudo do homem, através de seu corpo em movimento, nas relações com seu mundo interno e seu mundo externo”.

Segundo Beatriz Saboya (1990), este trabalho utiliza o corpo em movimento (consigo mesmo e na sua relação com o outro), a representação no objeto e a palavra na busca de 
uma harmonia espiralada entre as esferas sensório/motora, sentimento/emoção e pensamento/palavra. Utiliza a representação no objeto como meio e recurso de compreensão da realidade do ser, ao lado do trabalho corporal e da comunicação verbal. Faz-se necessário olhar um pouco mais o organismo vivo em suas três esferas, em integração com o meio. Quando há uma integração harmônica entre elas e há troca com o meio, o indivíduo está bem consigo mesmo e na relação com o mundo. Quando um destes elementos não flui, se estabelece a desarmonia e a falta de integração, no Eu comigo e/ou no Eu com o mundo.

Segundo Vitor da Fonseca (1998), a psicomotricidade pretende atingir, na sua ação educativa e terapêutica, a organização neuropsicomotora da noção do corpo como marco espaço-temporal do EU (concebido como unidade psicossomática), fundamental a qualquer processo de conduta ou de aprendizagem, ou seja, busca conhecer o corpo nas suas relações múltiplas: perceptiva, imagéticas, simbólicas e conceituais, que constitui um esquema representacional e uma supervivência singular, indispensável à integração, à elaboração e à expressão de qualquer ato ou gesto intencional. Pretende transformar o corpo num instrumento de ação sobre o mundo e num instrumento de relação e expressão com os outros, o que subentende um componente relacional intra e interpessoal determinante. A psicomotricidade constitui uma abordagem multidisciplinar do corpo e da motricidade humana. Seu objeto é o sujeito humano total e suas relações com o corpo, sejam elas integradoras, emocionais, simbólicas ou cognitivas, propondo-se desenvolver faculdades expressivas do sujeito, nas quais, por esse contexto assume uma dimensão educacional e terapêutica original, com objetivos próprios.

Em termos de matriz teórica, a psicomotricidade compreende, em síntese, um ramo interdisciplinar de conhecimentos, no qual se cruzam várias contribuições cientificas. Além dos conceitos psicobiológicos e psicofisiológicos inerentes ao estudo da função tônicopostural, as percepções e a motricidade expressiva, integram igualmente os conceitos: Psicológicos (desenvolvimento psicomotor, gênese da noção do corpo, formação de caráter e da personalidade, etc); Psiquiátricos (noção de inconsciente, emergência das pulsões, síndromes de despersonalização, anorexias mentais, hipocondrias, etc); Psicolingüísticos (linguagem pré-verbal, linguagem interior e gestual, etc); Fenomenológicos (o sentir o corpo como objeto afetivo, percepção corporal, espacialidade do próprio corpo, motricidade abstrata, intencionalidade motora, análise existencial dos problemas perceptivos e temporalidade como presença do mundo, etc); Sociológicos (comunicação não-verbal, proscênica, etc).

A psicomotricidade ilustra uma integração sistêmica entre corpo, cérebro e mente, numa inseparabilidade neurofuncional que revela uma síntese filogenética, ontogenética, retrogenética ao longo da vida e exclusiva da espécie humana.

Dada a circunstância da adaptação humana revelar uma integração sensorial complexa e um processamento cerebral de múltiplas motricidades (macro, micro, oro, grafo e sociomotora), a sua qualidade expressiva só pode verificar-se numa compatibilidade entre 
motivação e a interação do próprio indivíduo (do seu próprio self), ou seja, de sua somatognosia, da consciência do seu corpo. A idéia de que o cérebro controla a motricidade e recebe informação sensorial do corpo e do mundo implica numa comunicação, uma interação e um processo holístico e dinâmico de aprendizagem, baseada numa melodia neuronal, inicialmente imatura e desmatura, mas posteriormente madura e integrada.

Sem a psicomotricidada, a essência da adaptablidade criativa da espécie humana e sua propensão a resolver problema com soluções motoras não seriam possíveis; acrescentar ao mundo natural um mundo civilizacional não seria materializável.

É dentro desse sentido de integração multi e transdisciplinar que encerra o estudo da psicomotricidade e a sua estreita relação com a construção de saber.

\section{2 - A Construção do Saber}

O verbo ensinar é proveniente do latim insignari, que significa marcar um sinal, procurar a vida, desvendar e despertar para o conhecimento. O termo ensinagem reúne, então, a ação de ensinar, por parte do docente e a ação de aprender por parte do discente, como uma sociedade cooperativa e intencional para atingir a finalidade da construção do saber consciente, crítico e reflexivo, no enfrentamento não só da constituição da aprendizagem, mas também da reconstrução desses mesmos saberes dentro da sociedade globalizada que muda a todo instante.

O saber, algo intrinsecamente pessoal, se constitui no dínamo da ação, do desempenho e da criatividade em todas as esferas da vida. Cada aprendiz tem sua maneira própria de aprender ou de absorver conhecimento e formar "seu” saber. Cada um tem seu ritmo próprio, tem suas preferências e interesses.

O saber não é tão pouco específico, mas é o saber que ajuda a buscar, dentro e fora de cada um, o conhecimento necessário em face de cada desafio que a vida apresenta.

O saber é um estado de consciência que está além da compreensão cognitiva do conhecimento adquirido. Conteúdos são apenas células de informações trabalhadas na etapa inicial no longo processo de aprendizagem e de construção do saber.

A construção do conhecimento por parte do discente inclui várias etapas culminando com o "saber o quê”, o “saber como”, "saber por quê”, “saber para quê”. A constituição deste conhecimento é um processo que se estabelece no interior do sujeito da aprendizagem, sendo provocada pelo docente. Ao obter respostas a essas etapas do saber, o discente estabelece elos necessários para o fio condutor do conhecimento, em relação ao processo de ensino. Ao estabelecer elos, o sujeito em ação (discente), garante momentos construídos de forma dinâmica e global dentro de um processo de pensamento apossandose do significado da realidade concreta e mobilizando-se para o processo pessoal de aprendizagem.

Durante a construção do saber, se dá a aprendizagem significativa, onde é dado sentido à linguagem que é usada e relacionada ao conhecimento construído no cotidiano, com os fatos e a realidade do dia a dia, do discente que interage com os outros sujeitos da 
sociedade. Nesse tipo de aprendizagem, a interação é intencional e esquematizada, entre o discente, o docente e o que se deseja conhecer, morando aí a profundeza da relação psicomotora na construção do saber. O desafio da conquista do conhecimento significativo está alicerçado na parceria da construção do saber, na aventura do ensinar, do aprender e apreender. Integram-se aí movimentos, pensamentos e linguagem como mediação necessária à construção do saber do homem, texto e contexto da cultura. O que torna, a todos, a um só tempo, aprendizes e ensinantes pois, frente ao outro, reciprocamente, na inter-relação, passa-se e recebe-se, o que se é, as representações que se tem, sem que disto, na maioria das vezes, se aperceba com clareza. Todos os atributos que caracterizam o ser constroem-se na história de uma formação social, num movimento, num processo de relações familiares, grupais e intergrupais, que se estende ao longo da vida e, em meio ao qual, afetos, necessidades, valores, normas, imagens, símbolos, demandas e interesses articulam-se em constante movimento.

Sob essa ótica, o saber articula-se à própria condição do homem cujo movimento de construção do saber só encontra término na morte. Portanto, a construção do saber não se restringe, e sim se integra a processos complexos que envolvem o homem como um todo, através de seu corpo em movimento, nas suas relações internas e externas, no concreto de seu viver e de seu fazer, na dinâmica do viver, com a apropriação e expressão.

Sendo assim, ao processo educativo compete a tarefa de fornecer a consciência da realidade de um mundo complexo, agitado, e, ao mesmo tempo, fornecer a direção que permite navegar por ele.

Visto dessa maneira, a UNESCO através do "Relatório Delors” (apud, Morin, 2003) recomenda para a educação, neste início de século XXI, a adoção de quatro pilares fundamentais que são:

a) Aprender a conhecer - adquirir as competências para a compreensão, incluindo o domínio dos próprios instrumentos do conhecimento. Em síntese, quem aprende a conhecer aprende a aprender e essa aprendizagem é absolutamente essencial para as relações interpessoais, as capacidades profissionais e os fundamentos de uma vida digna. Essa primeira aprendizagem seria uma palavra de ordem que dá um basta à aprendizagem de saberes inúteis que entulham nossos currículos e, também, o fim de uma visão de que o ensino deve estar restrito a um certo número de horas por dia e de certo número de anos para sua conclusão. Em seu lugar devem imperar habilidades para se construir conhecimentos, exercitando os pensamentos, a atenção e a memória selecionando as informações que, efetivamente, possam ser contextualizadas com a realidade que se vive e capazes de serem expressas através de linguagens diferentes.

b) Aprender a fazer - embora quem aprende a conhecer já esteja aprendendo a fazer , esta segunda aprendizagem enfatiza a questão da formação profissional e o preparo para o mundo do trabalho. Que não se entenda aqui que o tema possa se referir ao Ensino Teórico ou algo similar, mas sim que a escola, desde a educação infantil, ressalte a importância de se pôr em prática os conhecimentos significativos ao trabalho 
futuro. Ensinar a fazer, portanto, não pode continuar significando "preparar alguém para uma tarefa determinada”, mas sim despertar e estimular a criatividade para que se descubra o valor construtivo do trabalho, sua importância como forma de comunicação entre o homem e a sociedade, seus meios como ferramentas de cooperação e para que transforme o processo de conhecimento em novos empreendimentos e em novos empregos.

c) Aprender a ser - retorna a idéia de que todo ser humano deve ser preparado inteiramente espírito e corpo, inteligência e sensibilidade, sentido estético e responsabilidade pessoal, ética e espiritualidade para elaborar pensamentos autônomos e críticos e também para formular os próprios juízos de valores, de modo a poder decidir, por si mesmo, como agir em diferentes circunstâncias da vida.

d) Aprender a conviver - a fim de participar e cooperar com os outros, em todas as atividades humanas envolvendo a compreensão do outro, a percepção das diferenças e interdependências, convivendo na tolerância, com solidariedade. Para que isso possa verdadeiramente acontecer é essencial que os docentes tenham coragem de desvestir a escola de sua fisionomia de quartel e deixar de ser um disfarçado campo de competições para, aos poucos, ir se transformando em um verdadeiro centro de descoberta do outro e também um espaço estimulador de projetos solidários e cooperativos, identificados pela busca de objetivos comuns.

\section{3 - Despertando o interesse da Comunidade Acadêmica do UniFOA para a importância do ser na sua totalidade}

Observa-se a partir da segunda metade deste século, a busca de novas formas de pensamento, um novo paradigma, um novo modelo de construção de saber, que valorize o sentimento, a intuição, a motivação, a percepção, a emoção, a espiritualidade com uma visão do ser na sua totalidade, numa relação indissociável com o meio físico do qual ele faz parte.

O holismo, enquanto prática intelectual voltada para a visão da totalidade, começa a ter espaço no meio acadêmico, provocando mudanças na ótica dos currículos de formação em diferentes campos, que se voltam para uma visão mais compreensiva, consciente, competente e integrada, da realidade.

De acordo com este novo paradigma da contemporaneidade é que pretendemos despertar o interesse da comunidade acadêmica do UniFOA para a necessidade de um reposicionamento do papel do docente em relação à transmissão do conhecimento. Faz-

se necessário que o docente não seja apenas um transmissor de conhecimentos e sim um companheiro de viagem junto ao discente nesta longa jornada do ensino superior; articulando a excelência, competência, empatia e autonomia dentro de um clima de 
respeito, capaz de fazer frutificar o diálogo, o debate, a cooperação, a consciência critica, a experimentação, a divergência, a oposição, a troca, o autoquestionamento, a reflexão etc.

O docente do UniFOA deve ser um observador, um interprete perspicaz, capaz de identificar os entraves que se estabelecem entre o par docente-discente, para melhor saber lidar com a teia das relações que se criam durante a construção do saber. Pois o mesmo é o eixo da atividade pedagógica e a ele é delegado um importante papel social, qual seja o de compreender o discente no âmbito de sua dimensão humana, na qual tanto os aspectos intelectuais, quanto os aspectos afetivos estão presentes e se interpenetram em todas as manifestações, impedindo ou facilitando a absorção e a construção do saber.

À comunidade acadêmica do UniFOA cabe o desafio de garantir o movimento, o fluxo de energia, a motivação, a troca, a empatia etc. Isso significa a manutenção do diálogo permanente voltado para o “indivíduo coletivo”, que reconhece a importância do outro, a existência de processos coletivos de construção do saber e a relevância de se criar ambientes de aprendizagem que favoreçam o desenvolvimento do conhecimento interdisciplinar e da criatividade ao processo educativo como um todo.

Portanto, nesta relação docente-discente, o afeto e o respeito devem estar sempre presentes.

\section{Considerações Finais}

A construção do saber é um caminho pelo qual o indivíduo torna-se homem continuamente. Nessa perspectiva, caracteriza-se como o movimento da vida. Não é um ato isolado, nem o somatório de momentos, mas um processo sutil que supõe mediações, implica apropriações e trocas que não se fazem sem o outro - singular e plural. É nessa relação, ao mesmo tempo pessoal e social, que a psicomotricidade pretende atingir, na sua ação educativa ou terapêutica, a organização neuropsicomotora da noção do corpo, como marco espaço - temporal do EU, fundamental a qualquer processo de conduta ou de aprendizagem.

Este trabalho tem a intenção de ser o começo de muitos outros que possam estar por vir com a finalidade de despertar o interesse da comunidade acadêmica do UniFOA para a importância do ser na sua totalidade (ser biopsicosocial).

Não tem a intenção de se apresentar como verdade absoluta, e sim de fomentar a reflexão da comunidade acadêmica no que diz respeito à troca, e despertar a consciência critica, autonomia e criatividade do discente, durante o processo educativo como um todo.

Eu diria que os educadores são como velhas árvores. Possui uma face, uma “estória” a ser contada. Habitam um mundo em que o que vale é a relação que os liga aos alunos, sendo que cada aluno é uma "entidade” sui generis, portador de um nome, também de uma “estória”, sofrendo tristezas e alimentando esperanças. 
E a educação é algo para acontecer neste espaço, invisível e denso que se estabelecem a dois. Espaço artesanal.

(Rubens Alves - Conversa com quem gosta de ensinar, 1983 p.17)

\section{Bibliografia}

ALMEIDA, A. R. S. A emoção em sala de aula. Campinas, Papirus, 1999

ALVES, R. Conversa com quem gosta de ensinar. 22 ed. São Paulo: Cortez, 1988 (p.47)

ANAIS DO IX CONGRESSO BRASILEIRO DE PSICOMOTRICIDADE: uma realidade transdisciplinar, Olinda: SBP (Sociedade Brasileira de Psicomotricidade), 2002.

BARTHES, R. Do obvio e lo obtuso, Madrid: Piados, 1986.

BASTIEN, C. Lê decalage entre logique et connaisscence, in Courrier du CNRS, n. 167 79, Sciences Cognitives, outobro, 1992.

BASTOS, L da R et al. Manual para elaboração de projetos e relatórios de pesquisas, teses e monografias. Rio de Janeiro: LTC (Livros Técnicos e Científicos), 2003.

BRASIL. Lei $\mathrm{n}^{\circ}$ 9394, de 20 de dezembro de 1996. Estabelece as Diretrizes e Bases da Educação Nacional. Diário Oficial da União, no 248, p. 27833-27841, 23 dez. 1996

BRAZIELLAS, M. de L. M. Questões da universidade contemporânea: contribuições para uma didática contextualizada no ensino superior. Rio de Janeiro: Editora Central Universidade Gama Filho, 1998.

CAMUS, L.L. O Corpo em Discussão, Porto Alegre: Artes Médicas, 1986.

FAVERO, M. de L. de A. A Universidade Brasileira em busca de sua identidade. Petrópolis: Vozes, 1977.

FONSECA, V da. Psicomotricidade: filogênese, ontogênese e retrogênese. Porto Alegre: Artes Médicas, 1998.

Artmed, 2004.

Psicomotricidade: perspectivas multidisciplinares. Porto Alegre: 
FRAGA, M. D. da. Universidade: concepções, conceitos, projetos, Dissertação (Mestrado em Educação), Fundação Getulio Vargas Bibliografia, (p. 24), 1982.

HOLANDA, A B. de. Novo Dicionário da Língua Portuguesa, 2004.

LEVIN, E. A Clínica Psicomotora: o corpo na linguagem. Petrópolis: Vozes, 2000

MARCONI, M de A., et al. Técnicas de Pesquisa. São Paulo: Atlas AS, 2002.

MORIN, E. Os sete saberes necessários à educação do futuro. São Paulo: Cortez. 2003.

SABOYA, B. Bases Psicomotoras: aspectos neuropsicomotores e relacionais no primeiro ano de vida. Rio de Janeiro: Trainee, 1990

\section{Informações bibliográficas:}

Conforme a NBR 6023:2002 da Associação Brasileira de Normas Técnicas (ABNT), este texto científico publicado em periódico eletrônico deve ser citado da seguinte forma:

FALCÃO, H. T.; RAMOS, C. D.; Pires, J.; Peixoto, M. C. S. Importância da Psicomotricidade na Construção do saber no Ensino Superior do Centro Universitário de Volta Redonda - UniFOA. Cadernos UniFOA, Volta Redonda, ano 2, nº. 3, mar. 2007.

Disponível em: <http://www.unifoa.edu.br/pesquisa/caderno/edicao/03/92.pdf> 